\title{
High mobility electron-conducting thin-film transistors by organic vapor phase deposition
}

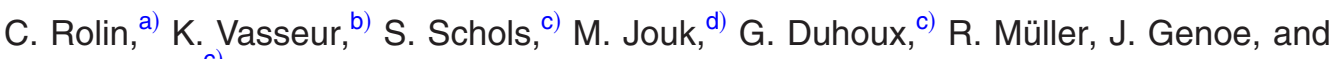 \\ P. Heremans ${ }^{\text {) }}$ \\ IMEC v.z.w., Kapeldreef 75, B-3001 Leuven, Belgium
}

(Received 28 April 2008; accepted 25 June 2008; published online 21 July 2008)

In this letter, we report on the growth of thin films of $N, N^{\prime}$-ditridecylperylene3,4,9,10-tetracarboxylic diimide (PTCDI- $\mathrm{C}_{13} \mathrm{H}_{27}$ ) by organic vapor phase deposition (OVPD). Uniform films are deposited with a material utilization efficiency of $59 \pm 4 \%$ and deposition rates up to $15 \AA / \mathrm{s}$. Top-contact transistors based on OVPD-grown PTCDI- $\mathrm{C}_{13} \mathrm{H}_{27}$ show high $n$-type mobilities (up to $0.3 \mathrm{~cm}^{2} / \mathrm{V} \mathrm{s}$ ) and reproducible characteristics. The influence of deposition parameters on electrical properties is discussed. () 2008 American Institute of Physics. [DOI: 10.1063/1.2958229]

In the recent years, the field of organic $n$-type semiconductors has experienced major progress, driven among others by potential applications in complementary organic circuitry. ${ }^{1}$ Several promising electron-conducting materials based on oligothiophene derivatives, ${ }^{2,3}$ on naphthalene ${ }^{4}$ and perylene ${ }^{5}$ derivatives have emerged. These combine high electron mobilities and reasonable environmental stabilities. Most of these materials are nonsoluble small molecules. They deliver their good results in thin films grown using vacuum thermal evaporation (VTE). VTE is a technique that allows a high degree of purity and a good morphological control, but its operation is delicate on large area substrates and it has a low production throughput. An alternative technique to VTE is organic vapor phase deposition (OVPD) ${ }^{6-8}$ In OVPD, the source material is sublimed into a stream of hot carrier gas. The molecules undergo a convective transport through a hot-wall chamber to a cooled substrate on which they condense to form a film. This technique allows excellent structural control ${ }^{9,10}$ combined with high deposition throughputs, ${ }^{11,12}$ which renders it attractive for industrial applications. However OVPD has never been used for the fabrication of $n$-type organic thin film transistors (TFTs).

In this work, we study the growth by OVPD of the $n$-type organic semiconductor $N, N^{\prime}$-ditridecylperylene3,4,9,10-tetracarboxylic diimide (PTCDI- $\mathrm{C}_{13} \mathrm{H}_{27}$ ). The nature of the side chains of PTCDI derivatives plays a crucial role in controlling the molecular packing conformation and thus the electronic structure of the thin film. ${ }^{13}$ Therefore, tuning the side chain architecture offers an opportunity to optimize the transport properties. With two long straight aliphatic side chains, PTCDI- $\mathrm{C}_{13} \mathrm{H}_{27}$ appears to be one of the most successful PTCDI derivatives for TFT fabrication. Top contact transistors based on thin films of this molecule deposited by VTE delivered good characteristics with electron mobilities up to $0.6 \mathrm{~cm}^{2} / \mathrm{V} \mathrm{s}^{4}$ A record TFT mobility of

\footnotetext{
${ }^{a}$ Also with: P.C.P.M., Université Catholique de Louvain, 1348 Louvain-LaNeuve, Belgium. Electronic mail: rolinc@imec.be.

${ }^{b)}$ Also at the N.T.M..Dept., Katholieke Universiteit Leuven, 3001 Leuven, Belgium.

${ }^{c)}$ Also at the E.E.Dept., Katholieke Universiteit Leuven, 3001 Leuven, Belgium.

d) Also at the C.R.H.E.A.-C.N.R.S., 06560 Valbonne, France.
}

$2.1 \mathrm{~cm}^{2} / \mathrm{V} \mathrm{s}$ was obtained after an annealing treatment in vacuum. ${ }^{15}$

PTCDI- $\mathrm{C}_{13} \mathrm{H}_{27}$ was bought from Aldrich and purified once by gradient sublimation. A differential scanning calorimetry (DSC) measurement of the powder at atmospheric pressure indicated a melting point of $347^{\circ} \mathrm{C}$. Moreover, to evaluate the vapor pressure of the material around its melting point, a thermogravimetric analysis of the powder was carried out following the guidelines given in Ref. 16. We extracted values of $175 \mathrm{~kJ} / \mathrm{mol}$ for the enthalpy of evaporation $\left(\Delta H_{\text {vap }}\right)$ and of $260 \mathrm{~J} / \mathrm{mol} \mathrm{K}$ for the entropy of evaporation $\left(\Delta S_{\text {vap }}\right)$. Those values are valid in a temperature range of $100{ }^{\circ} \mathrm{C}$ above the melting point.

Approximately $500 \mathrm{mg}$ of the purified powder was loaded in the source cell of the OVPD system (described in Ref. 12). For PTCDI- $\mathrm{C}_{13} \mathrm{H}_{27}$ deposition, the furnace temperature $T_{\text {fur }}$ was set between 330 and $360{ }^{\circ} \mathrm{C}$ and the $\mathrm{N}_{2}$ carrier gas flow through the source cell $Q_{s}$, preheated to the source cell temperature, was varied from 10 to 500 SCCM (SCCM denotes cubic centimeter per minute at STP). The source flow was diluted with a supplemental preheated $\mathrm{N}_{2}$ carrier gas flow so that the total flow $Q_{\text {tot }}$ was always 1000 SCCM. At the entrance of the deposition chamber, the gas is evenly distributed onto the substrate holder by means of a hot showerhead located $4 \mathrm{~cm}$ above the substrate surface. The substrate temperature $T_{\text {sub }}$ was set between 30 and $120{ }^{\circ} \mathrm{C}$ and the chamber pressure $P_{\text {chamb }}$ was kept at a constant pressure of 5 torr.

The deposition rate $r_{\text {dep }}$ is calculated after growth, using the thickness from an ex situ ellipsometric measurement. It varies with substrate temperature, chamber pressure, total carrier gas flow, source cell flow, and furnace temperature. The latter parameter has the most significant impact on the deposition rate. By pushing the furnace temperature up to $390{ }^{\circ} \mathrm{C}$, films were produced with deposition rates of $15 \AA / s$. However, in order to limit the thermal stress endured by the source material, most of the experiments were conducted at furnace temperatures below $360{ }^{\circ} \mathrm{C}$, setting an upper limit of about $2 \AA /$ s. Figure 1(b) depicts the calibration curves of the deposition rate as a function of source flow and furnace temperature. These calibration curves reveal the source cell efficiency as follows. In the source cell, the molar flow of organic molecules leaving the source cell $q_{\text {org }, s}$ is 


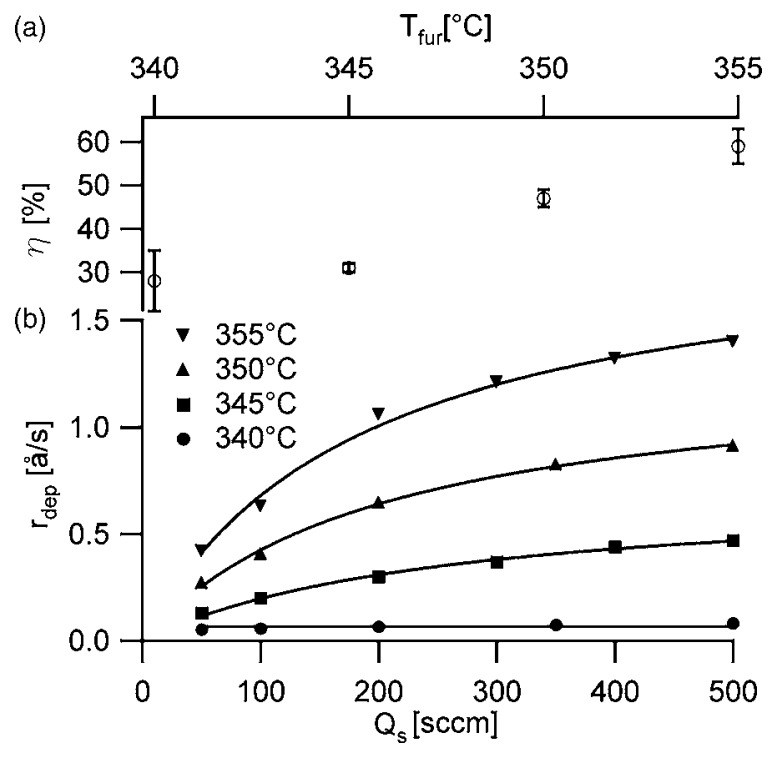

FIG. 1. (a) Extracted deposition efficiencies $\eta$ as a function of $T_{\text {fur }}$ (b) Calibration curves of $r_{\text {dep }}$ as a function of $\mathrm{Q}_{s}$ and $T_{\text {fur }}$. $\mathrm{Q}_{\text {tot }}=1000 \mathrm{SCCM}$, $T_{\text {sub }}=50^{\circ} \mathrm{C}$ and $P_{\text {chamb }}=5$ torr.

determined both by the carrier gas molar flow $q_{s}$ and by the concentration of organic molecules,

$$
q_{\mathrm{org}, s}=q_{s} \frac{P_{\mathrm{org}, s}}{P_{s}},
$$

where $P_{s}$ is the total pressure in the source cell and $P_{\text {org }, s}$ is the partial pressure of organic molecules. In a regime situation, the carrier gas constantly blows organic molecules away from the source cell, therefore lowering their partial pressure under their equilibrium vapor pressure $P_{\mathrm{org}, s}^{\mathrm{eq}}$. Shtein et al. propose the following equation to evaluate $P_{\text {org }, s}$ as a function of the source flow: ${ }^{17}$

$$
\frac{P_{\mathrm{org}, s}}{P_{\mathrm{org}, s}^{\mathrm{eq}}}=\frac{1}{\frac{q_{s}}{k P_{s}}+1},
$$

where $k$ is the rate constant of evaporation and recondensation. It is reasonable to assume that the molar flow $q_{\mathrm{org}, s}$ is conserved from the source cell down to the deposition chamber. The molar flow of organic material effectively deposited on the substrate surface $q_{\text {org,dep }}$ is then a fraction of the flow entering the chamber,

$$
q_{\text {org }, \mathrm{dep}}=\eta q_{\mathrm{org}, s} \quad 0 \leqslant \eta \leqslant 1 .
$$

The efficiency factor $\eta$ represents the coupling of the susceptor to the showerhead. It includes all the events occurring between the ejection of the organic molecules from the showerhead nozzles to their final condensation onto the substrate. Bringing together Eqs. (1)-(3), one gets the expression of the deposited flow as a function of the source flow,

$$
q_{\mathrm{org}, \mathrm{dep}}=\eta \frac{P_{\mathrm{org}, s}^{\mathrm{eq}}}{P_{s}} \cdot \frac{q_{s}}{\frac{q_{s}}{k P_{s}}+1} .
$$

An equation similar to Eq. (4) is presented in Ref. 18 in order to interpret results obtained with another OVPD system. By means of an appropriate unit change, ${ }^{19}$ the experimental data in Fig. 1(b) is fitted by Eq. (4), using $\eta$ and $k$ as Author complimentary copy. Redistribution subject to AIP

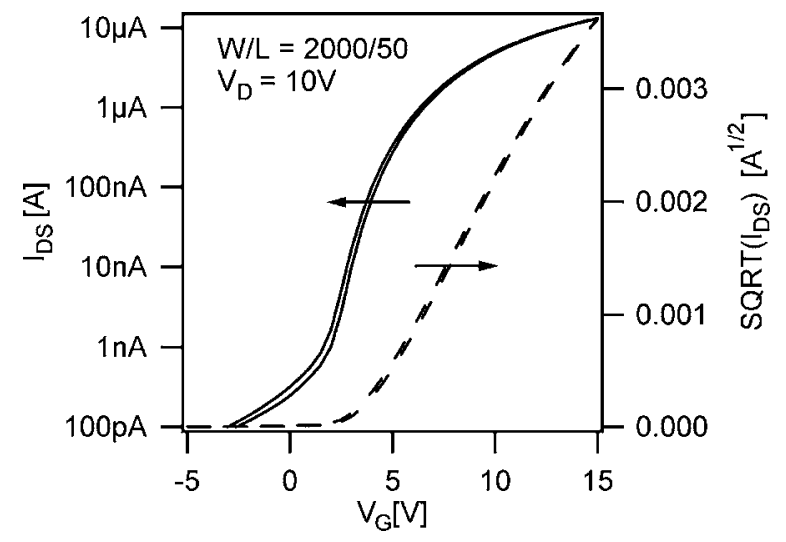

FIG. 2. Typical $I_{\mathrm{DS}}-V_{\mathrm{GS}}$ characteristics for OVPD deposited PTCDI-C $\mathrm{C}_{13} \mathrm{H}_{27}$ top-contact TFTs measured in the saturation mode. Maximum mobility is $0.3 \mathrm{~cm}^{2} \mathrm{~V} / \mathrm{s}$.

fitting parameters. Figure 1(a) shows the deposition efficiencies extracted for the different furnace temperatures. At a total flow of 1000 SCCM, a maximum deposition efficiency of $59 \pm 4 \%$ is obtained at a furnace temperature of $355^{\circ} \mathrm{C}$.

Top-contact TFTs were fabricated using a highly doped $n^{+}$silicon wafer as gate, covered with a $120 \mathrm{~nm}$ thick thermal $\mathrm{SiO}_{2}$ layer as gate dielectric. Prior to PTCDI- $\mathrm{C}_{13} \mathrm{H}_{27}$ deposition, the gate dielectric was treated with a $5 \mathrm{~nm}$ thick poly-( $\alpha$-methyl-styrene) film $(\mathrm{P} \alpha \mathrm{MS}) .^{20} \mathrm{~A} \sim 50 \mathrm{~nm}$ thick PTCDI-C ${ }_{13} \mathrm{H}_{27}$ film was grown by OVPD with deposition rates ranging from 0.1 up to $15 \AA / s$. Finally, source and drain contacts of $0.6 \mathrm{~nm} \mathrm{LiF} / 100 \mathrm{~nm} \mathrm{Al}$ were deposited by evaporation through a shadow mask, delivering TFTs with a channel width of $2000 \mu \mathrm{m}$ and a channel length varying between 50 and $200 \mu \mathrm{m}$. Prior to metallization, the devices were exposed for less than $30 \mathrm{~s}$ to ambient atmosphere. Transistor measurements were carried out inside a glove box under protected atmosphere $\left(\mathrm{N}_{2}\right)$. Figure 2 represents typical transfer curves for such TFTs measured in the saturation regime. With slightly positive onset and threshold voltages (2.5 and $3.6 \mathrm{~V}$, respectively, in Fig. 2), On-off current ratios above $10^{5}$ and a negligible hysteresis, transistor characteristics are well behaved. Thin film mobilities were calculated as described in Ref. 21, using relative dielectric constant values of 3.9 for $\mathrm{SiO}_{2}$ and 2.2 for $\mathrm{P} \alpha \mathrm{MS}$, separately obtained from capacitance-voltage measurements. Mobilities as high as $0.3 \mathrm{~cm}^{2} / \mathrm{V} \mathrm{s}$ were extracted in saturation. These results are comparable to the ones published by Gundlach et al. with VTE-deposited PTCDI- $\mathrm{C}_{13} \mathrm{H}_{27}$ thin films and $\mathrm{LiF} / \mathrm{Al}$ top contacts. ${ }^{14}$ Moreover, a saturation mobility over $0.1 \mathrm{~cm}^{2} / \mathrm{V} \mathrm{s}$ was measured on 40 successive samples produced with the same batch of source material over a time period of four months.

In an effort to relate electrical performances to deposition parameters, transistors were fabricated using PTCDI- $\mathrm{C}_{13} \mathrm{H}_{27}$ thin films grown by OVPD at various substrate temperatures and deposition rates. Even though the substrate temperature, by promoting molecular surface diffusion and lowering nucleation rates, ${ }^{9}$ has a strong impact on thin film morphology, its effect on electrical performances remains unclear. At substrate temperatures from 80 to $120{ }^{\circ} \mathrm{C}$, TFT saturation mobility values evolve in a nonmonotonic erratic manner. This variability could be due to uncontrolled structural reorganization effects. Indeed, the DSC analysis reveals that in this temperature range, license or copyright, see http://apl.aip.org/apl/copyright.jsp 


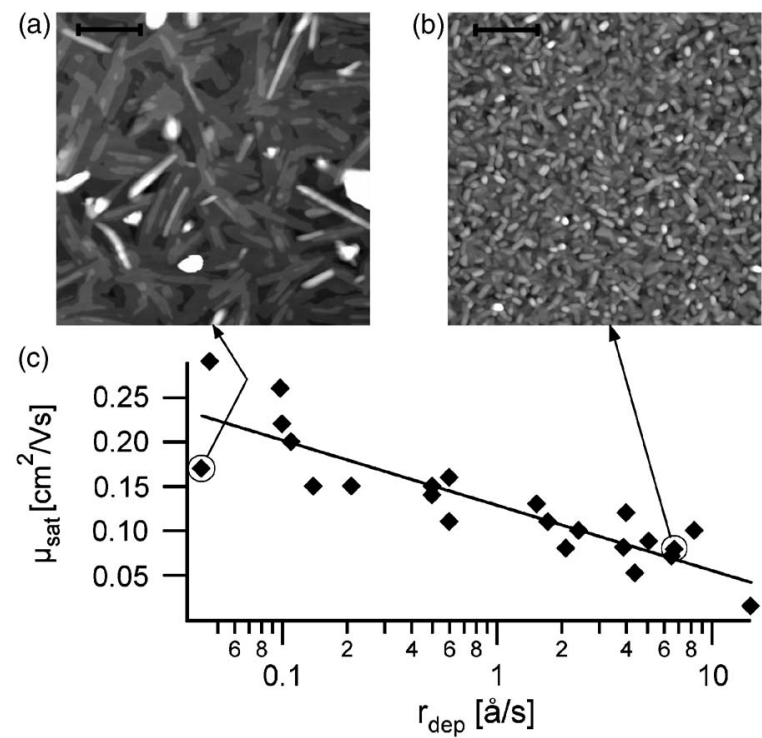

FIG. 3. [(a) and (b)] Tapping-mode AFM images of $30 \mathrm{~nm}$ thick PTCDI- $\mathrm{C}_{13} \mathrm{H}_{27}$ thin films deposited on P $\alpha$ MS with deposition rates of (a) $0.04 \AA / \mathrm{s}$ and (b) $6.7 \AA / \mathrm{s}$, respectively. The length of the bars is $0.5 \mu \mathrm{m}$. (c) Saturation mobilities of OVPD-deposited PTCDI- $\mathrm{C}_{13} \mathrm{H}_{27}$ TFTs as a function of the deposition rate. The straight line serves as a guide for the eye. All films were grown with $\mathrm{Q}_{\text {tot }}=1000 \mathrm{SCCM}, T_{\text {sub }} \sim 50^{\circ} \mathrm{C}$ and $P_{\text {chamb }}=5$ torr.

PTCDI- $\mathrm{C}_{13} \mathrm{H}_{27}$ undergoes two successive phase transitions. On the other hand, as shown in Fig. 3(c), the TFT saturation mobility linearly decreases with the logarithm of the deposition rate. The PTCDI- $\mathrm{C}_{13} \mathrm{H}_{27}$ thin film morphology is influenced by the deposition rate. At low rates [Fig. 3(a)], large needle-shaped islands grow on top of a layered structure. At high rates [Fig. 3(b)], small and uniform grains are formed. The strong increase in grain density with the deposition rate is a sign of many grain boundaries crossing the transistor channel, even in the first few monolayers of the film. This loss of continuity is a likely cause for the lowering of electrical performances with the deposition rate.

In summary, the OVPD technique was applied to the growth of a high mobility n-type material: PTCDI- $\mathrm{C}_{13} \mathrm{H}_{27}$. Uniform films were deposited with a material utilization efficiency of $59 \pm 4 \%$ and deposition rates up to $15 \AA /$ s. Topcontact transistors were fabricated with OVPD-deposited PTCDI- $\mathrm{C}_{13} \mathrm{H}_{27}$ thin films. These display low threshold voltages, high $I_{\mathrm{on}} / I_{\mathrm{off}}$ ratios, low hysteresis, and $n$-type mobilities up to $0.3 \mathrm{~cm}^{2} / \mathrm{V} \mathrm{s}$ in a long-term reproducible manner. Those characteristics advantageously compare to the ones measured on similar devices based on VTE-deposited thin films. The best electrical performances were obtained for the films grown at low deposition rates. This work shows that high mobility small-molecular electron-conducting organic semiconductors can be successfully deposited with a technique well suited for industrial applications.

This work was performed in a collaboration between IMEC and TNO in the frame of the HOLST Centre. C.R. acknowledges the F.R.I.A. and S.S. acknowledges the F.W.O. Vlaanderen for Ph.D. grants. The authors acknowledge the financial support of the EC-funded Integrated Projects POLYAPPLY (IST No. 507143) (http://www.polyapply.org) and NAIMO (NMP4-CT-2004-500355).

${ }^{1}$ C. R. Newman, C. D. Frisbie, D. A. da Silva Filho, J.-L. Brédas, P. C. Ewbank, and K. R. Mann, Chem. Mater. 16, 4436 (2004).

${ }^{2}$ A. Facchetti, M. Mushrush, H. E. Katz, and T. J. Marks, Adv. Mater. (Weinheim, Ger.) 15, 33 (2003).

${ }^{3}$ R. J. Chesterfield, C. R. Newman, T. M. Pappenfus, P. C. Ewbank, M. H. Haukaas, K. R. Mann, L. L. Miller, and C. D. Frisbie, Adv. Mater. (Weinheim, Ger.) 15, 1278 (2003).

${ }^{4}$ H. E. Katz, A. J. Lovinger, J. Johnson, C. Kloc, T. Siegrist, W. Li, Y. Y. Lin, and A. Dodabalapur, Nature (London) 404, 478 (2000).

${ }^{5}$ P. R. L. Malenfant, C. D. Dimitrakopoulos, J. D. Gelorme, L. L. Kosbar, T. O. Graham, A. Curioni, and W. Andreoni, Appl. Phys. Lett. 80, 2517 (2002).

${ }^{6}$ OVPD is a technology by UDC exclusively licensed to AIXTRON for equipment manufacturing.

${ }^{7}$ The term OVPD is a trademark of AIXTRON.

${ }^{8}$ M. A. Baldo, M. Deutsch, P. E. Burrows, H. F. Gossenberger, M. Gerstenberg, V. S. Ban, and S. R. Forrest, Adv. Mater. (Weinheim, Ger.) 10, 1505 (1998).

${ }^{9}$ F. Yang, M. Shtein, and S. R. Forrest, Nat. Mater. 4, 37 (2005).

${ }^{10}$ F. Yang, K. Sun, and S. R. Forrest, Adv. Mater. (Weinheim, Ger.) 19, 4166 (2007).

${ }^{11}$ M. Shtein, P. Peumans, J. B. Benziger, and S. R. Forrest, Adv. Mater. (Weinheim, Ger.) 16, 1615 (2004).

${ }^{12}$ C. Rolin, S. Steudel, K. Myny, D. Cheyns, S. Verlaak, J. Genoe, and P. Heremans, Appl. Phys. Lett. 89, 203502 (2006).

${ }^{13}$ R. J. Chesterfield, J. C. McKeen, C. R. Newman, P. C. Ewbank, D. A. da Silva, J.-L. Brédas, L. L. Miller, K. R. Mann, and C. D. Frisbie, J. Phys. Chem. B 108, 19281 (2004).

${ }^{14}$ D. J. Gundlach, K. P. Pernstich, G. Wilckens, M. Gruter, S. Haas, and B. Batlogg, J. Appl. Phys. 98, 064502 (2005).

${ }^{15}$ S. Tatemichi, M. Ichikawa, T. Koyama, and Y. Taniguchi, Appl. Phys. Lett. 89, 112108 (2006)

${ }^{16}$ K. Yase, Y. Takahashi, N. Arakato, and A. Kawazu, Jpn. J. Appl. Phys., Part 1 34, 636 (1995).

${ }^{17}$ M. Shtein, H. F. Gossenberger, J. B. Benziger, and S. R. Forrest, J. Appl. Phys. 89, 1470 (2001).

${ }^{18}$ T. X. Zhou, T. Ngo, J. J. Brown, M. Shtein, and S. R. Forrest, Appl. Phys. Lett. 86, 021107 (2005).

${ }^{19}$ The conversion is as follows: $q_{\text {org,dep }}=r_{\text {dep }} 1 e-10 A_{\text {sub }} \cdot \delta$ where $A_{\text {sub }}=2 e$ $-3 \mathrm{~m}^{2}$ is the substrate area and $\delta=3320.7 \mathrm{~mol} / \mathrm{m}^{3}$ is the PTCDI- $\mathrm{C}_{13} \mathrm{H}_{27}$ density, as given in Ref. 15 .

${ }^{20}$ T. W. Kelley, P. F. Baude, C. Gerlach, D. E. Ender, D. Muyres, M. A. Haase, D. E. Vogel, and S. D. Theiss, Chem. Mater. 16, 4413 (2004).

${ }^{21}$ C. Horowitz, Adv. Mater. (Weinheim, Ger.) 10, 365 (1998). 